\title{
Posttraumatic Stress Disorder Symptoms and Posttraumatic Growth Following Indirect Trauma from the Sewol Ferry Disaster, 2014
}

\author{
Aekyeong Wong ${ }^{1}$, Hong-seock Lee ${ }^{1 凶}$, Heung-pyo Lee ${ }^{2}$, Yun-kyeung Choi ${ }^{3}$, and Jae-ho Lee ${ }^{3}$ \\ ${ }^{1}$ Posttraumatic Growth Center, Department of Psychiatry, Kangnam Sacred Heart Hospital, Hallym University Medical Center, Seoul, \\ Republic of Korea \\ 2Department of Psychology, Daegu Cyber University, Daegu, Republic of Korea \\ ${ }^{3}$ Department of Psychology, Keimyung University, Daegu, Republic of Korea
}

Psychiatry Investig 2018;15(6):613-619

https://doi.org/10.30773/pi.2017.12.03

In the original publication, reference number 20 was incorrect. It was printed as "Aldwin CM, Levenson MR, Spiro A 3rd. Vulnerability and resilience to combat exposure: can stress have lifelong effects? Psychol Aging 1994;9:34-44." It should be revised as follows: “Aldwin CM. Stress, Coping, and Development: An Integrative Perspective. New York: Guilford Press; 1994."

(c) This is an Open Access article distributed under the terms of the Creative Commons Attribution Non-Commercial License (https://creativecommons.org/licenses/bync/4.0) which permits unrestricted non-commercial use, distribution, and reproduction in any medium, provided the original work is properly cited. 